\title{
O ATENDIMENTO AEROMÉDICO NO EXTREMO OESTE DE SANTA CATARINA
}

\author{
Vanessa Fátima SCHONS ${ }^{1}$, Alessandro VERFFEL ${ }^{2}$, Nádia BENDER ${ }^{3}$, \\ Alexssandro Marcos ROSA ${ }^{4}$
}

\begin{abstract}
RESUMO: Em dezembro de 2015 foi firmado um convênio entre a Secretaria Municipal de Saúde de Chapecó e a Polícia Civil de Santa Catarina, por meio do Serviço Aeropolicial de Fronteira da Polícia Civil (SAERFRON), dando início às atividades do Serviço de Atendimento e Resgate Aeromédico, o SARA. Esse trabalho tem por objetivo apresentar o SARA de Chapecó, Santa Catarina. Estudo documental, retrospectivo com abordagem quantitativa. A coleta de dados foi realizada através das fichas de atendimento do SARA no período de julho de 2019. Foram incluídas na pesquisa todas as ocorrências de voo para atendimento, resgate e/ou transporte realizado no período dezembro de 2015 a maio de 2019. Para análise dos dados foram quantificadas e agrupadas em tabelas. Na nossa realidade, extremo Oeste de Santa Catarina, abrangência de oitenta e seis municípios da área de fronteira (Brasil-Argentina) atendidos pelo SARA, este desempenha um papel fundamental, pois existem muitos "vazios assistenciais" em nossa região, ou seja, locais com recursos estruturais e médicos limitados. Esse fator tem influencia direta no resultado do atendimento prestado. O tempo de deslocamento entre as cidades de nossa abrangência também é um fator que influencia nesse resultado.
\end{abstract}

PALAVRAS-CHAVES: Resgate aéreo, Medicina Aeroespacial, Paciente Crítico INTRODUÇÃO

A origem do transporte aeromédico e da Medicina Aeroespacial remete à história da Medicina de Guerra com sua assistência aos feridos nas batalhas e a remoção desses militares e, eventualmente, civis. Da mesma forma que a guerra trouxe grandes catástrofes para a humanidade, trouxe progressos à ciência médica e desenvolvimento técnico-científico (Gomes e cols; 2013).

O Transporte Aeromédico é uma modalidade de deslocamento de paciente utilizada principalmente quando se fala de enfermos em estado crítico e, em muitas ocasiões, representa a única opção para que o indivíduo receba assistência em um centro especializado nas suas afecções e com tempo resposta hábil (Montezeli e cols; 2012).

1. Enfermeira Intervencionista no Serviço de Atendimento e Resgate Aeromédico - SARA, Chapecó - SC. Graduada pela Universidade Federal de Santa Maria - UFSM. Especialista na Atenção ao Paciente Crítico pelo Grupo Hospitalar Conceição - GHC, Porto Alegre - RS. Pós Graduação em Transporte Aeromédico e Medicina Aeroespacial pela CENSUPEG (em andamento).

2. Médico intervencionista do Serviço de Atendimento e Resgate Aeromédico - SARA, Chapecó -SC. Graduado pela Universidade Federal de Santa Maria - UFSM. Médico regulador e Intervencionista do SAMU Extremo Oeste.

3. Enfermeira Intervencionista no Serviço de Atendimento e Resgate Aeromédico - SARA, Chapecó - SC.

4. Médico intervencionista do Serviço de Atendimento e Resgate Aeromédico - SARA, Chapecó -SC. Médico requlador e Intervencionista do SAMU Extremo Oeste. 
Umas das modalidades do atendimento pré-hospitalar é através do emprego de aeronaves. Os helicópteros são considerados transportes do Tipo E, ou seja, são aeronaves de asas rotativas utilizadas para transportes interhospitalares de pacientes e para ações de resgate. $O$ atendimento feito por aeronaves deve ser sempre considerado como de Suporte Avançado de Vida SAV (BRASIL, 2006).

A importância da utilização de ambulância tipo $E$ é evidente pela velocidade e versatilidade no atendimento ao paciente crítico que por meio de transporte terrestre seria inviável pelo trânsito e áreas de difícil acesso (LACERDA, ARAÚJO, NETA; 2017).

A aeronave para remoção de pacientes possui espaço reduzido e o paciente é posicionado na maca no sentido transversal, na qual a equipe médica permanece de joelhos junto do paciente. A falta de mobilidade e o espaço reduzido limitam as intervenções e procedimentos em voo, por isso a importância da estabilização do quadro da vítima transportada e o planejamento do transporte (LACERDA, ARAÚJO, NETA; 2017).

Em Dezembro de 2015, foi firmado um convênio entre a Secretaria Municipal de Saúde de Chapecó e a Polícia Civil de Santa Catarina, por meio do Serviço Aeropolicial de Fronteira da Polícia Civil (SAERFRON), dando início às atividades do Serviço de Atendimento e Resgate Aeromédico, o SARA. O serviço conta com uma aeronave de asa rotativa, tipo Esquilo AS 350 B2, é um helicóptero monoturbina leve para até seis pessoas a bordo.

O SARA é um serviço de atendimento e resgate aeromédico, que tem por objetivo principal levar assistência qualificada e especializada a locais de recursos médicos limitados e para pacientes com necessidades de intervenções específicas frente a algum caso crítico. Realiza atendimentos em situações extra-hospitalares para vítimas de traumas diversos, o que caracteriza a atividade do serviço como sendo uma forma de atendimento primário, que visa à estabilização do quadro clínico e a remoção para o atendimento definitivo no serviço de referência. Realiza ainda, transporte interhospitalar nos casos em que o tempo resposta é fundamental para o melhor desfecho na condição clínica do paciente. 


\section{OBJETIVO}

Apresentar o Serviço de Atendimento e Resgate Aeromédico - SARA de Chapecó, Santa Catarina.

\section{METODOLOGIA}

Estudo documental, retrospectivo com abordagem quantitativa. $\mathrm{O}$ cenário da pesquisa foi serviço de atendimento e resgate aeromédico - SARA de Chapecó, Santa Catarina. A coleta de dados foi realizada através das fichas de atendimento do serviço aeromédico do SARA no período de julho de 2019. Foram incluídas na pesquisa todas as ocorrências de voo para atendimento, resgate e/ou transporte realizado no período dezembro de 2015 a maio de 2019. Para análise dos dados foram quantificadas e agrupadas em tabelas.

\section{RESULTADOS E DISCUSSÃO}

Esse trabalho buscou demonstrar a evolução na quantidade do número de pacientes atendidos pelo SARA, serviço de atendimento e resgate aeromédico do oeste de Santa Catarina, no período de dezembro de 2015 a Maio de 2019.

\section{ATENDIMENTOS SARA}

\begin{tabular}{|c|c|}
\hline PERIODO & $\mathbf{N}^{\circ}$ ATENDIMENTOS \\
\hline 2015 (Dezembro) & 05 \\
\hline 2016 & 107 \\
\hline 2017 & 125 \\
\hline 2018 & 163 \\
\hline 2019 (Jan-Mai) & 59 \\
\hline TOTAL & $\mathbf{4 5 9}$ \\
\hline
\end{tabular}

Números de atendimentos aeromédicos realizados pela equipe SARA no período de dezembro de 2015 a Maio de 2019.

ATENDIMENTOS PRIMARIO E SECUNDARIO

\begin{tabular}{|c|c|c|}
\hline PERIODO & PRIMÁRIO & SECUNDÁRIO \\
\hline 2017 & 34 & 91 \\
\hline 2018 & 82 & 81 \\
\hline 2019 & 23 & 36 \\
\hline TOTAL - 347 & $\mathbf{1 3 9}$ & $\mathbf{2 0 8}$ \\
\hline
\end{tabular}

Número de atendimentos primário e secundário realizados pela equipe do SARA de Janeiro de 2017 a Maio de 2019. 
Pode-se perceber que houve um crescimento com o passar dos anos, principalmente no período de 2017/2018, no qual houve um aumento de $23,31 \%$ no numero de atendimentos, comparando com o período de 2016/2017 que foi de $14,4 \%$.

Também podemos notar o incremento no número de atendimentos primários de $2017 / 2018$, na ordem de $141 \%$, indicando um entendimento maior no emprego do SARA, nas ocorrências em que o tempo resposta é primordial para redução da morbimortalidade, como nos casos de acidentes de trânsito em rodovias e traumas.

Quanto aos atendimentos secundários, que se caracterizam pelo transporte de pacientes que necessitam de atendimento especializado em alta complexidade, o numero de ocorrências se manteve constante no período $2017 / 2018$.

\section{CONCLUSÃO}

Na nossa realidade, extremo Oeste de Santa Catarina, abrangência de oitenta e seis municípios da área de fronteira (Brasil-Argentina) atendidos pelo serviço de atendimento e resgate aeromédico - SARA, este desempenha um papel fundamental. Ainda existem muitos "vazios assistenciais" em nossa região, ou seja, locais com recursos estruturais e médicos limitados. Esse fator tem influencia direta no resultado do atendimento prestado. O tempo de deslocamento entre as cidades de nossa abrangência também é um fator que influencia nesse resultado.

Ao analisar a literatura percebemos que o serviço aeromédico ainda é um assunto novo, porém os dados demonstram que o serviço aeromédico vem ganhando espaço na aérea médica de resgate e, principalmente quando se trata do paciente critico, na qual o tempo resposta é fundamental para o desfecho favorável com significativa redução na morbimortalidade dos pacientes atendidos. 


\section{REFERÊNCIAS}

Brasil. Ministério da Saúde. Política Nacional de Atenção às Urgências. Brasilia: MS; 2006. Available from: http://bvsms.saude.gov.br/bvs/publicacoes/politica_nacional_atencao_urgencia s 3ed.p df GomesMAV, Alberti LR, Ferreira FL, Gomes VM. Aspectos históricos do transporte aeromédico e da medicina aeroespacial - revisão. Rev Med Minas Gerais 2013; 23(1): 116-123116.

Lacerda LS, Araújo ERM, Neta FLA. Transporte aeromédico no estado do Piauí: perfil das ocorrências. Ver Pre Infec e Saúde [Internet].2017;3(2):20-26. Available from: http://www.ojs.ufpi.br/index.php/nupcis/article/view/6453

Scuissiato DR, Boff LV, Rocha RR, Montezeli JH, Bordon MT, Peres AM. Compreensão de enfermeiros de bordo sobre seu papel na equipe multiprofissional de transporte aeromédico. Rev Bras Enferm, Brasília 2012 julago; 65(4): 614-20. 